University of Montana

ScholarWorks at University of Montana

6-1999

\title{
Biological-Control Herbivores May Increase Competitive Ability of the Noxious Weed Centaurea Maculosa
}

\author{
Ragan M. Callaway \\ University of Montana - Missoula, Ray.Callaway@mso.umt.edu
}

Thomas H. DeLuca

Wendy M. Belliveau

Follow this and additional works at: https://scholarworks.umt.edu/biosci_pubs

Part of the Biology Commons

Let us know how access to this document benefits you.

\section{Recommended Citation}

Callaway, Ragan M.; DeLuca, Thomas H.; and Belliveau, Wendy M., "Biological-Control Herbivores May Increase Competitive Ability of the Noxious Weed Centaurea Maculosa" (1999). Biological Sciences Faculty Publications. 70.

https://scholarworks.umt.edu/biosci_pubs/70

This Article is brought to you for free and open access by the Biological Sciences at ScholarWorks at University of Montana. It has been accepted for inclusion in Biological Sciences Faculty Publications by an authorized administrator of ScholarWorks at University of Montana. For more information, please contact scholarworks@mso.umt.edu. 


\title{
BIOLOGICAL-CONTROL HERBIVORES MAY INCREASE COMPETITIVE ABILITY OF THE NOXIOUS WEED CENTAUREA MACULOSA
}

\author{
Ragan M. Callaway, ${ }^{1,3}$ Thomas H. Deluca, ${ }^{2}$ and Wendy M. Belliveau ${ }^{1}$ \\ ${ }^{1}$ Division of Biological Sciences, University of Montana, Missoula, Montana 59812 USA \\ ${ }^{2}$ School of Forestry, University of Montana, Missoula, Montana 59812 USA
}

\begin{abstract}
Biocontrol organisms are generally applied in an attempt to reduce the vigor of target species and provide native species with an competitive advantage. We tested the effectiveness of a widely used biocontrol moth, Agapeta zoegana (knapweed root moth) for two years in the field and found that it had no significant direct effect on the biomass of Centaurea maculosa (spotted knapweed), one of the most destructive invasive plants in North America. Instead of releasing a native grass from competition, the reproductive output of Festuca idahoensis planted with Centaurea was significantly lower when neighboring Centaurea had been attacked by Agapeta. In a greenhouse experiment, we found that Festuca planted in pots with Centaurea that had been attacked by Trichoplusia ni (another nonnative herbivore) had significantly smaller root systems than when they were planted with Centaurea that were protected from herbivory. Root systems of Centaurea that had been attacked by Trichoplusia exuded higher levels of total sugars, but not total phenols. We hypothesize that moderate herbivory stimulated compensatory growth, induced the production of defense chemicals that also had allelopathic effects, or stimulated root exudates that altered the relationship between Centaurea and Festuca via soil microbes. Our data suggest that herbivory may increase the negative effects of $C$. maculosa on neighboring plants, and that some biocontrols may have indirect negative effects on native species that are not currently recognized.
\end{abstract}

Key words: Agapeta zoegana Lin; biocontrols; Centaurea maculosa Lam.; competition; consumers; exotics; Festuca idahoensis Elmer; herbivory; indirect and higher order interactions; invasive plants; knapweed; Trichoplusia ni Hübner.

\section{INTRODUCTION}

Exotic invasive species pose a serious threat to global biological diversity by causing rapid, local replacement and eradication of native species (Julien 1987, Drake et al. 1989). Many promising weapons in the fight against exotic invaders are biological: predators, herbivores, and parasites imported from the invasive species' place of origin. The use of biocontrols has been highly successful in some cases, reducing the spread of invasive plants (Huffaker and Kennett 1959, Cullen 1973, McEvoy et al. 1991) and providing "green" alternatives for pest management. However, biocontrols sometimes attack nontarget native species, compete with native species, and have unwanted community and ecosystem effects (Howarth 1991, Simberloff and Stiling 1996, Louda et al. 1997). Ecologists have also expressed alarm about the widespread use of biocontrols, because biocontrols may exert indirect effects that are not yet understood (Howarth 1991).

Centaurea maculosa Lam. (Asteraceae, spotted knapweed) is one of the most economically destructive exotic invaders in the northwestern United States and southwestern Canada, and it infests $>4$ Mha in North

Manuscript received 3 July 1997; revised 11 May 1998; accepted 18 May 1998; final version received 29 June 1998.

${ }^{3}$ E-mail: callaway@selway.umt.edu
America (Müller-Schärer and Schroeder 1993). Centaurea invasion is often characterized by dense stands and virtually complete competitive exclusion of native species. Although Centaurea species have been highly successful in North America, they are usually minor components of their native communities. Biological control agents were first introduced to control knapweed species in 1970, and now 11 species of insects have been introduced to North America for this purpose (Müller-Schärer 1991). One of the most promising is the moth Agapeta zoegana Lin (Tortricidae, knapweed root moth) the larvae of which are specialist herbivores on the taproots of a few related Centaurea species (Müller 1989). We have also observed other nonnative herbivores consuming Centaurea, including the common cabbage looper, Trichoplusia ni Hübner (Noctuidae).

The use of biocontrols to weaken or eliminate exotic plants is based on a general, but untested, assumption: invasive exotics are successful because they have escaped intense consumer pressure in their native habitat. Implicit in this assumption is that direct top-down effects in these systems are paramount and that indirect effects are weak. However, in some circumstances, indirect effects in natural communities can be stronger than direct effects (Strauss 1991, Wooton 1994). Despite the fundamental importance of understanding how 
biocontrols indirectly affect native plants, examination of the effects of biocontrols are almost always limited to the direct effects of the biocontrol on the target weed and the potential direct effects of the biocontrol on natives related to the target weed. Here, we studied the direct effects of Agapeta and Trichoplusia on the target species C. maculosa and its indirect effects on a nontarget native bunchgrass in common-garden plots and in greenhouse conditions.

\section{Methods}

\section{Common garden experiment}

A field experiment was designed to test the direct effect of Centaurea on Festuca idahoensis Elmer., the direct effects of Agapeta on Centaurea, and the indirect effect of Agapeta on Festuca. This experiment was carried out at the Diettart Experimental Gardens in Missoula, Montana, USA. Soils at the site are in the Bigarm Gravelly Loam Series (Loamy-skeletal, mixed, frigid Typic Haploxerols). Twelve Centaurea and 12 Festuca idahoensis individuals were planted in each of 20 $0.25-\mathrm{m}^{2}$ plots, with individual plants alternating by species in rows and columns of a grid. The locations of these plots within the sample area were chosen randomly, and each plot was $50 \mathrm{~cm}$ from neighboring plots on all sides. Mesh cages were placed over all 20 plots, and four Agapeta zoegana moths were introduced into each of a randomly chosen subset of 10 plots in June 1994 (see Müller-Schärer 1991). Agapeta zoegana is a native of Eurasia, as is Centaurea, and is now being used extensively in efforts to control the spread of Centaurea. We acquired Agapeta from the Montana State University Experiment Station in Corvallis, Montana. Agapeta moths lay their eggs on the stems and at the root-shoot interface of Centaurea plants, and the larvae hatch from the eggs in 7-10 d and immediately burrow into the taproot to feed (Weeden et al. 1997). In western Europe, the moth is univoltine, and the main period of feeding occurs during the fall and spring (Müller et al. 1988). Adult moths emerge from knapweed roots in early July-early September. In another 10 plots, Festucas were planted with conspecific competitors, rather than Centaurea. These plots were also treated with cages, although no moths were introduced. Herbivory on Festuca by native insects was not controlled, but vertebrate herbivores were excluded from the experimental garden. In October 1994 we measured the basal areas of the four central Festuca individuals in each plot. In September 1995, two growing seasons after introducing Agapeta, total aboveground biomass of Centaurea and Festuca was harvested, and the total number of Festuca florets in each plot were counted. Bunchgrass meristems accrue laterally; thus, basal diameter is an important measure of vegetative growth. We did not reapply Agapeta in the second year of the experiment. In the plots with only Festuca plants, total floret number was halved. This was done in order to compare reproductive production between single-species plots and plots containing both Centaurea and Festuca.

To provide the abiotic background for this experiment, and to investigate the potential confounding effects of soil water availability on treatments, soil moisture was measured using Frequency Domain Reflectometry (Troxler [Triangle Park, North Carolina], Sentry 200-AP). To investigate the potential confounding effects of differences of soil nutrient availability on treatment effects, ion exchange resin bags were used to accumulate available nitrogen and phosphorus from 15 April-15 October 1994 (Binckley and Vitousek 1991). Resin bags were buried $15 \mathrm{~cm}$ deep near the center of each of the 30 garden plots. Nitrogen was measured as $1 \mathrm{~mol} / \mathrm{L} \mathrm{KCl}$ extractable ammonium and nitrate, and phosphorus was measured as $1 \mathrm{~mol} / \mathrm{L} \mathrm{KCl}$ extractable phosphorus.

Signs of Agapeta herbivory were observed in the taproots of numerous plants in each of the treatment plots at the time of the harvest, but root damage was not quantified. We observed mature Agapeta moths in Centaurea foliage $2 \mathrm{yr}$ after establishing the treatments, suggesting that Agapeta may have dispersed to treatment plots that were intended to be free from herbivory. However, we observed no sign of larval damage in any of the Centaurea taproots in the no-herbivory treatments. All ANOVA comparisons were conducted with fixed-effect models.

\section{Greenhouse experiment}

A greenhouse experiment was designed to more carefully control the intensity of herbivory and to test the effects of a leaf herbivore. Twenty-six Centaurea at the rosette stage were collected in the field, and each was transplanted into an 8-L pot containing field soil of the same type used in the common garden experiment and grown in a naturally lighted greenhouse. On sunny days, irradiation ranged from $450-1400 \mu \mathrm{mol} \cdot \mathrm{m}^{-2} \cdot \mathrm{s}^{-1}$, and temperatures ranged from $24-32^{\circ} \mathrm{C}$. Festuca were grown from seed in silica sand for $8 \mathrm{wk}$, and then one individual was transplanted into each pot with a Centaurea. Five days after transplanting the Festucas, a single cabbage looper caterpillar (Trichoplusia ni) was placed inside a cage (made from transparent acetate and fine mesh) around the Centaurea-Festuca pairs in 13 pots. These were left until 10-25\% of the Centaurea leaf area was either eaten or was discolored, due to caterpillar herbivory. We acquired Trichoplusia from the Cornell University Experiment Station, Geneva, New York, USA. Trichoplusia is not currently used as a biocontrol for C. maculosa, but we have observed Trichoplusia eating Centaurea in the field, and, in earlier experiments, we found it to consume the weed rapidly. Our primary reasons for using Trichoplusia were the ease of application and estimating rates of herbivory, which was not possible with Agapeta. Another 13 Centaurea-Festuca pairs were protected from 
caterpillar herbivory with the same cages used for the herbivory treatment. Plants were harvested 8 wk after Trichoplusia were removed. They were then dried at $60^{\circ} \mathrm{C}$ and weighed. During the $8 \mathrm{wk}$ of the experiment, we did not observe other insects on our test plants; however, in the eighth week aphids were seen on several Centaurea plants, and the experiment was abruptly terminated.

A single $2 \mathrm{~cm}$ diameter polyester capsule (Unibest, Bozeman, Montana, USA) containing $1100 \mathrm{~m}^{2}$ surface area of nonionic carbonaceous resin (Ambersorb 563, Rohm and Haas, Philadelphia, Pennsylvania, USA) was buried within the root mass of each Centaurea at the time of transplanting. When the plants were harvested, capsules were removed and frozen until analysis. Capsules were thawed to room temperature, and exudates were eluted from the resins using a sequential extraction of five pore volumes $(25 \mathrm{ml})$ of distilled deionized water, followed by five pore volumes of $50 \%$ redistilled methanol. The extracts were then analyzed for total hydrolyzable sugars, total phenols, and ultraviolet (UV) absorption spectra. Total sugars were determined by reacting $5 \mathrm{ml}$ of extract with $10 \mathrm{ml}$ of anthrone reagent, followed by analysis against glucose standards at $625 \mathrm{~nm}$ (Brink et al. 1960). Total phenolic compounds were determined in methanol extracts, as described by Price and Butler (1977). Ultraviolet absortion spectra were recorded for all extracts, by performing a scan of light absorption in the range 350-190 nm.

\section{RESULTS}

Plots in all treatments were very similar in soil water status, ammonium, and nitrate. Soil moisture content at 15 - and $30-\mathrm{cm}$ depths did not vary significantly between treatments in either year (repeated-measures ANOVA, $F_{\text {treatment } \times \text { time at } 15 \mathrm{~cm}}=0.93 ; \mathrm{df}=5,59 ; P=$ $0.606 ; F_{\text {treatment } \times \text { time at } 30 \mathrm{~cm}}=1.04 ; \mathrm{df}=5,59 ; P=0.412$ ). Likewise, soil nutrients did not vary among treatments. Available soil nitrate for the Festuca alone, FestucaCentaurea, and Festuca-Centaurea-Agapeta treatments, combined, were the following: $5.25 \pm 1.31 \mu \mathrm{g} / \mathrm{g}$ resin (mean $\pm 1 \mathrm{SE}$ ) for nitrate, $4.17 \pm 0.93 \mu \mathrm{g} / \mathrm{g}$ for ammonium, and $0.49 \pm 0.13 \mu \mathrm{g} / \mathrm{g}$ for phosphorus. These values did not vary significantly between treatments during the first year of the study (ANOVA, $\mathrm{NO}_{3}$ : $F_{\text {treatment }}=0.149 ; \mathrm{df}=2,29 ; P=0.862 ; \mathrm{NH}_{4}: F_{\text {treatment }}$ $=0.319 ; \mathrm{df}=2,29 ; P=0.729 ;$ Phosphous: $F_{\text {treatment }}$ $=1.74 ; \mathrm{df}=2,29 ; P=0.194)$.

In the field, Centaurea severely suppressed Festuca reproduction (Fig. 1) and aboveground biomass (Festuca alone, $0.85 \pm 0.17 \mathrm{~g} /$ plant, Festuca with Centaurea, $0.33 \pm 0.11 \mathrm{~g} / \mathrm{plant}$; ANOVA, $F=7.62$; df $=1$, $19 ; P=0.012$ ), but Centaurea biomass was not significantly affected by exposure to Agapeta herbivory for two growing seasons (ANOVA, $F=1.68$; $\mathrm{df}=1$, $19 ; P=0.21)$. We conducted a power test (Cohen 1988) on data for Centaurea's response to herbivory and

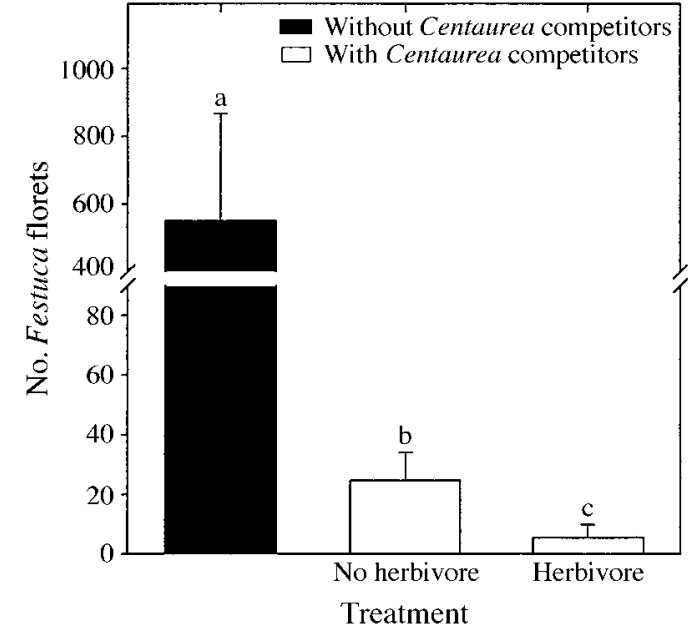

FIG. 1. Total number of florets produced in $0.25 \mathrm{~m}$ common-garden plots by Festuca idahoensis without Centaurea maculosa neighbors (corrected for the number of Festuca), or with C. maculosa neighbors and either with or without Agapeta zoegana biocontrols. Error bars show +1 SE. Significant differences among treatments are denoted by different letters $(a, b$, and $c)$ above the error bars (ANOVA, postANOVA Tukey).

found that it would have taken a sample size of 50 to have an $80 \%$ chance of detecting a biologically real difference of the observed size. We found no significant effects of water or soil nutrients as covariates. Festuca did not benefit from herbivory on Centaurea. In fact, when Agapeta were allowed to attack Centaurea, the number of Festuca florets produced per plot decreased (Fig. 1; ANOVA, including soil moisture in plots as a covariate, $F_{\text {treatment }}=4.43 ; \mathrm{df}=1,19 ; P=0.050$ ). When neighbor Centaureas were exposed to herbivory, individual Festuca basal area was $4.49 \pm 1.45 \mathrm{~cm}^{2}$, compared to $7.25 \pm 1.25 \mathrm{~cm}^{2}$ when there was no herbivory on Centaurea, but the difference was not significant (treatment by plot ANOVA, $F_{\text {treatment }}=2.14 ; P=$ 0.149 ), and there were no significant effects of water or nutrients as covariates. Festuca biomass was 0.49 $\pm 0.16 \mathrm{~g}$ when grown with Centaurea without Agapeta, and $0.33 \pm 0.05 \mathrm{~g}$ when Agapeta was applied to Centaurea (ANOVA, $F=1.380$; df $=1,19 ; P=0.268$, no significant effects of covariates).

We could not accurately measure root biomass in the field, although it was measured in the greenhouse. In the greenhouse experiment, Festuca root biomass was $0.33 \pm 0.04 \mathrm{~g}$ when neighboring Centaurea had been attacked by cabbage loopers, but was $0.41 \pm 0.04 \mathrm{~g}$ when Centaurea was protected from herbivory (Fig. 2; ANOVA, initial Festuca size as covariate, $F_{\text {treatment }}=$ $6.75 ; \mathrm{df}=1,25 ; P=0.016)$. Herbivory on Centaurea did not significantly reduce the shoot or total biomass of the invasive weed. Centaurea did not flower during the experiment; therefore, we do not have measurements of reproduction to compare to the field experiments. Total sugars sorbed to nonionic resins and ex- 


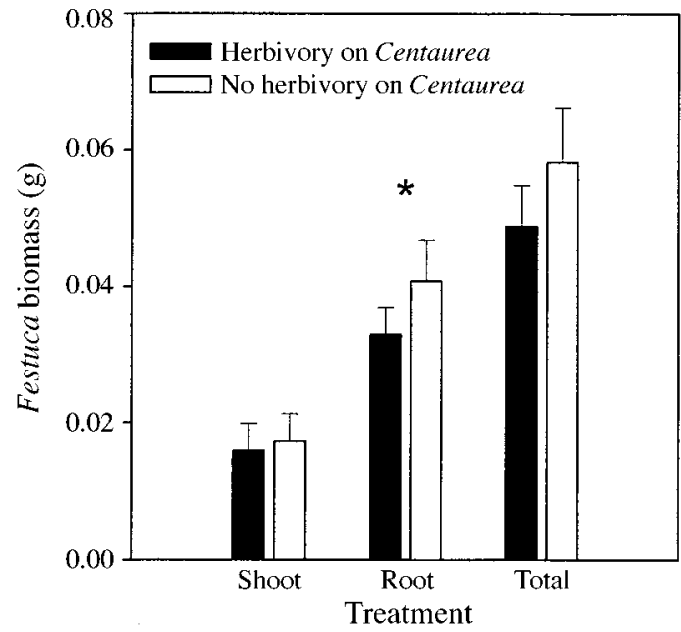

FIG. 2. Biomass of Festuca idahoensis with Centaurea maculosa neighbors that had either been grazed by Trichoplusia $n i$ or protected from grazing. Error bars show +1 SE. The asterisk denotes a significant difference between treatments; ANOVA, $P<0.05$, initial size of Festuca was used as a covariate.

tracted by water or methanol were significantly greater in resin capsules under Centaurea that had been attacked by Trichoplusia (Fig. 3; ANOVA, $F=5.602$; df $=1,24 ; P=0.027$ ). Total methanol-extractable phenols captured on the resin capsules did not differ among the treatments, but they tended to be greater under Centaurea that had been exposed to herbivory. (ANOVA with cosine-transformed data, $F=0.697$; df $=1,25 ; P=0.413)$.

\section{DISCUSSION}

Contrary to expectations for biocontrols in general, in both experiments, Centaurea that had been exposed to herbivory had greater negative effects on Festuca than Centaurea that were kept free from herbivory; and, in the field experiment, Agapeta did not significantly decrease Centaurea biomass. Müller-Schärer (1991) and Steinger and Müller-Schärer (1992) also found that intermediate levels of Agapeta herbivory did not reduce shoot biomass, shoot number, or seed output of C. maculosa; but such levels of herbivory did reduce plant height and reproductive mass.

The mechanisms for the indirect effect of these herbivores on Festuca are unclear; however, there are three salient hypotheses that are applicable to both experiments. First, Centaurea plants may have grown faster after they experienced herbivory and, thereby, reduced resources available for other species. This is supported by the absence of a difference in total biomass between Centaurea exposed to herbivory and Centaurea protected from herbivory in the greenhouse and field experiments. Such herbivory-induced growth is termed "compensatory growth," and it has been widely reported and debated (Maschinski and Whitham 1989,
Alward and Joern 1993, Belsky et al. 1993). However, we know of no instance in which a compensatory response has increased the competitive ability of a plant. The intensity of compensatory growth is highly dependent on particular abiotic and biotic conditions (Maschinski and Whitham 1989, Alward and Joern 1993), and, if compensatory effects are restricted to certain soil conditions (high-nitrate low-phosphorus conditions, in our study), it may not be important in other environments. In Switzerland, Steinger and Müller-Schärer (1992) found that Centaurea maculosa ssp. rhenana exhibited root compensatory growth when consumed by Agapeta and Cyphocleonas achates (which is another root herbivore used as a biocontrol) and that the compensatory response was affected by soil nitrogen content and competition from Festuca pratensis.

A second hypothesis is that biocontrols induced the production of defensive secondary metabolites that also functioned as antiplant allelopaths. Others have found dual antiherbivore-allelopathic roles in inducible plant metabolites (Lovett and Holt 1995), and increased allelopathic productivity under stress (Tang et al. 1995). Cnicin, a defensive chemical in Centaurea species that has been found to deter herbivory (Landau et al. 1994), is also suspected to have allelopathic properties (Fletcher and Renney 1963, Muir and Majak 1983, Kelsey and Locken 1987). However, cnicin is primarily restricted to the trichomes on Centaurea leaves, and herbivory is unlikely to increase its production (R. Kelsey, personal communication). Centaurea maculosa roots have been found to reduce the growth rates of $F$. idahoensis roots near them, and this effect was ameliorated by activated carbon (Belliveau and Callaway, unpublished manuscript). Activated carbon is a potent

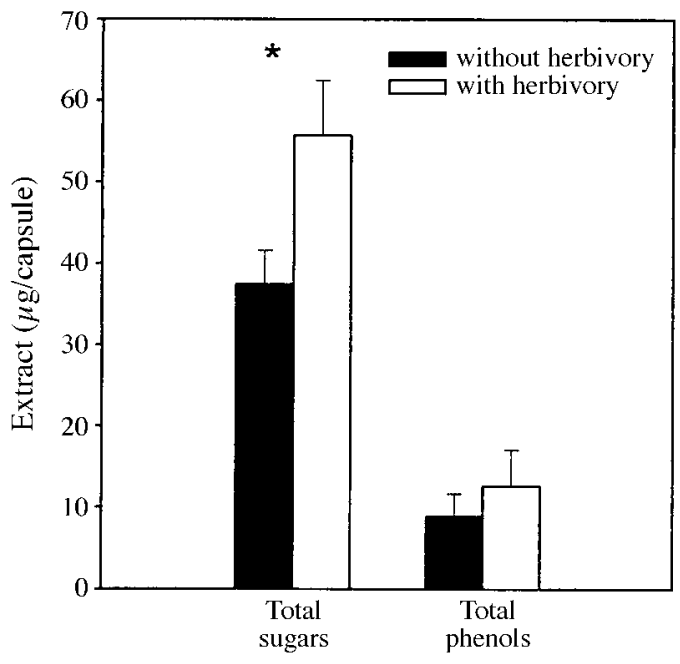

FIG. 3. Total sugars and phenols extracted from resin capsules that had been inserted in Centaurea roots. Error bars show +1 SE. The asterisk denotes a significant difference between treatments; ANOVA, $P<0.05$. 
adsorbent of charged organic molecules (Cheremisinoff and Ellerbusch 1978). Biologically active volatile polyacteylenes have also been isolated from the roots of other Centaurea species (Bohlmann et al. 1966) and the roots of C. maculosa (R. Kelsey, personal communication). We found no significant difference in phenol concentrations in the extracts of resin capsules under plants, with and without herbivory, in the greenhouse; but the trend was similar to that of total sugar concentrations. We do not know if root herbivory in field conditions also altered root exudation.

Sugars, or compounds exuded from the roots attached to sugars, may have altered microbe-plant and plant-plant interactions. Sugar release to the rhizosphere of plants, which increased for Centaurea when grazed by Trichoplusia, is an important and readily available source of energy for microorganisms (Ocampo and Azcon 1985). Sugars in the rhizosphere help drive a number of important processes, including freeliving $\mathrm{N}$ fixation and mineral immobilization and solublization (Tate 1995). Relationships between root exudation of sugars and mycorrhizal infection has been reported (Ratnayake et al. 1978, Graham et al. 1981, Same et al. 1983). Differences in root exudate quantity or composition may also affect mycorrhizal mediation of the interaction between Centaurea and Festuca. UVabsorption spectrographs of fescue, knapweed, and bulk soil resin extracts (T. H. DeLuca, unpublished data) indicated that a significant portion of carbon detected in the methanol had UV absorbtion spectra similar to that of flavonoid compounds. Recently, root flavonoids have been identified as important signals of microbial response in the rhizosphere at micromolar and even nanomolar concentrations (Becard et al. 1992). Higher levels of sugars in the exudates of attacked Centaurea may indicate higher levels of exuded flavonoids, because flavonoids that are released as root exudates are often glycosylated to increase their solubility (Markham 1981, Varin 1992) and transport out of the root. The anthrone reagent used in this study hydrolyzes complex polysaccharides and glycosides and reacts with the released monosaccharides; thus, detection of soluble sugars in these studies may, in part, have been related to the presence of glycosylated flavonoids. Exudate effects on mycorrhizae have the potential to be important, as our previous research has shown that Centaurea develops substantial arbuscular mycorrhizae (AM) infections in the field in intermountain grasslands, and they have large effect on interactions between Centaurea and Festuca idahoensis (Marler et al. 1999).

The results of our experiments corroborate each other, but the greenhouse experiment does not provide an explicit test of the field experiment. We used a generalist herbivore in the greenhouse to facilitate precise levels of herbivory; however, Trichoplusia ate leaves, and herbivory occurred in a short intense bout. In contrast, Agapeta ate roots, and over a long period of time.
Second, we could not measure root biomass in the field nor reproductive output in the greenhouse (plants did not flower). Therefore, direct comparisons of the experiments are unclear. However, the fact that herbivory on Centaurea showed significant negative indirect effects on Festuca, under two very different sets of experimental conditions, suggests that these general indirect effects are robust.

Many invasive plants, such as a number of Centaurea species, are rapidly replacing native communities, and some risk in the application of biocontrols may be warranted. Nevertheless, our data suggest that herbivory by biocontrols can make an already superior competitor even better, especially if biocontrols do not badly damage or kill the target plant. Thus, evaluation of biocontrols prior to their use should include some screening for their indirect effects as has been suggested by others (Simberloff and Stiling 1996). A fundamental rationale for using biocontrols to suppress invasive plants is that, by weakening the invader, natives may gain a competitive advantage. Our data suggest that this may not always be the case.

\section{ACKNOWLEDGMENTS}

We thank Erick Greene for first observing unusual patterns in our data, and Tom Martin and Cathy Zabinski for helpful suggestions throughout. We thank Erik Ashehoug, Jennifer Costich, Shannon Garner, Marilyn Marler, Paul Ridenour, Raven Stevens, Michael Wojdylak, and Todd Wojtowitz for fruitful discussion or field assistance. We are indebted to Jim Story at the Montana State Experiment Station for supplying us with Agapeta, and providing us with valuable information, and to the Cornell Experiment Station at Geneva for supplying us with Trichoplusia. This work was supported in part by NSF EPSCoR grant OSR-955450 to Dr. Jack Stanford at the University of Montana and NSF DEB 9726829 to R. M. Callaway and C. Zabinski.

\section{Literature Cited}

Alward, R. D., and A. Joern. 1993. Plasticity and overcompensation in grass responses to herbivory. Oecologia 95: 358-364.

Becard, G., D. D. Douds, Jr., and P. E. Pfeffer. 1992. Extensive hyphal growth of vesicular-arbuscular mycorrhizal fungi in the presence of $\mathrm{CO}_{2}$ and flavonols. Applied and Environmental Microbiology 58:821-825.

Belsky, A. J., W. P. Carson, C. L. Jensen, and G. A. Fox. 1993. Overcompensation by plants: herbivore optimization or red herring? Evolutionary Ecology 7:109-121.

Binkley, D., and P. Vitousek. 1991. Soil nutrient availability. Pages 75-96 in R. W. Pearcy, J. R. Ehleringer, H. A. Mooney, and P. W. Rundel, editors. Plant physiological ecology. Chapman and Hall, London, UK.

Bohlmann, F., K.-M. Rode, and C. Zdero. 1966. Neue polyine der Gattung Centaurea L. Chemische Berichte 99:35443551 .

Brink, R. H., P. Dubach, and D. L. Lynch. 1960. Measurement of carbohydrate in soil hydrolysates with antrhone. Soil Science 89:157-166.

Cheremisinoff, P. N., and F. Ellerbusch. 1978. Carbon adsorption handbook. Ann Arbor Science Publications, Ann Arbor, Michigan, USA.

Cohen, J. 1988. Statistical power analyses for the behavioral sciences. Second edition. Lawrence-Erlbaum, Hillsdale, New Jersey, USA. 
Cullen, J. M., P. F. Kable, and M. Catt. 1973. Nature 244: 462-464.

Drake, J. A., H. A. Mooney, F. Di Castri, R. H. Groves, F. J. Krueger, M. Rejmanek, and M. Williamson. 1989. Biological invasions: a global perspective. John Wiley and Sons, Chichester, UK.

Fletcher, R. A., and A. J. Renney. 1963. A growth inhibitor found in Centaurea spp. Canadian Journal Plant Science 43:475-481.

Graham, J. H., R. T. Leonard, and J. A. Menge. 1981. Membrane-mediated decrease in root exudation responsible for phosphorus inhibition of vesicular-arbuscular mycorrhiza formation. Plant Physiology 68:548-552.

Howarth, F. G. 1991. Environmental impact of classical biological control. Annual Review of Entomology 36:485509.

Huffaker, C. B., and C. E. Kennett. 1959 Journal of Range Management 12:69-82.

Julien, M. H. 1987. Biological control of weeds-a world catalogue of agents and their target weeds. Second edition. C. A. B. International, Wallingford, UK.

Kelsey, R. G., and L. J. Locken. 1987. Phytotoxic properties of cnicin, a sesquiterpene lactone from Centaurea maculosa (spotted knapweed). Journal of Chemical Ecology 13:1933.

Landau, I., H. Müller-Schärer, and P. I. Ward. 1994. Influence of cnicin, a sesquiterpene lactone of Centaurea maculosa (Asteraceae), on specialist and generalist insect herbivores Journal of Chemical Ecology 20:929-942.

Louda, S. M., D. Kendall, J. Connor, and D. Simberloff 1997. Ecological effects of an insect introduced for the biological control of weeds. Science 277:1088-1090.

Lovett, J. V., and A. C. H. Holt. 1995. Allelopathy and selfdefense in barley. Pages 170-183 in Inderjit, K. M. M., Dakshini, and F. A. Einhellig, editors. Allelopathy. American Chemical Society, Washington, D.C., USA.

Markham, K. R. 1981. Techniques of flavonoid identification. Academic Press, New York, New York, USA.

Marler, M. J., C. A. Zabinski, and R. M. Callaway. 1999. Mycorrhizae indirectly enhance competitive effects of an invasive forb on a native bunchgrass. Ecology, in press.

Maschinski, J., and T. G. Whitham. 1989. The continuum of plant responses to herbivory: the influence of plant association, nutrient availability and timing. American Naturalist 134:1-19.

McEvoy, P., C. Cox, and E. Coombs. 1991. Successful biological control of ragwort. Ecological Applications 1: 430-442.

Muir, A. D., and W. Majak. 1983. Allelopathic potential of diffuse knapweed (Centaurea diffusa) extracts. Canadian Journal of Plant Sciences 63:989-996.

Müller, H. 1989. Structural analysis of the phytophagous insect guilds associated with the roots of Centaurea maculosa Lam., C. diffusa Lam., and C. vallesiaca Jordan in Europe. I. Field observations. Oecologia. 78:41-52.
Müller, H., D. Schroeder, and A. Gassmann. 1988. Agapeta zoegana (L.) (Lep.: Cochylidae), a suitable prospect for the biological control of spotted and diffuse knapweed, Centaurea maculosa Lam. and C. diffusa Lam. (Compositae) in North America. Canadian Entomologist 120:109-124.

Müller-Schärer, H. J. 1991. The impact of root herbivory as a function of plant density and competition: survival, growth, and fecundity of Centaurea maculosa in field plots. Journal of Applied Ecology 28:759-776.

Müller-Schärer, H., and D. Schroeder. 1993. The biological control Centaurea spp. in North America: do insects solve the problem? Pesticide Science 37:343-353.

Ocampo, J. A., and R. Azcon. 1985. Relationship between the concentration of sugars in the roots and VA mycorrhizal infection. Plant and Soil 86:95-100.

Price, M. L., and L. G. Butler. 1977. Rapid visual estimation and spectroscopic determination of tannin content of sorghum grain. Journal of Agriculture and Food Chemistry 25:1268-1273.

Ratnayake, M., R. T. Leonard, and J. A Menge. 1978. Root exudation in relation to supply of phosphorus and its possible relevance to mycorrhizal formation. New Phytologist 81:543-552.

Same, B. I., A. D. Robson, and L. K. Abbott. 1983. Phosphorus, soluble carbohydrates, and endomycorrhizal infection. Soil Biology and Biochemistry 15:593-597.

Simberloff, D., and P. Stiling. 1996. How risky is biocontrol? Ecology 77:1965-1974.

Steinger, T., and H. Müller-Schärer. 1992. Physiological and growth responses of Centaurea maculosa (Asteraceae) to root herbivory under varying levels of interspecific plant competition and soil nitrogen availability. Oecologia 91: 141-149.

Strauss, S. Y. 1991. Indirect effects in community ecology: their definition, study, and importance. Trends in Ecology and Evolution 6:206-210.

Tang, C., W. Cai, K. Kohl, and R. K. Nishimoto. 1995. Plant stress and allelopathy. Pages 142-157 in Inderjit, K. M. M., Dakshini, and F. A. Einhellig, editors. Allelopathy. American Chemical Society, Washington, D.C., USA.

Tate, R. L. 1995. Soil microbiology. Wiley, New York, New York, USA.

Varin, L. 1992. Flavonoid sulfation: phytochemistry, enzymology, and molecular biology. Pages 233-254 in H. A. Stafford and R. K. Inbrahim, editors. Phenolic metabolism in plants. Recent advances in phytochemistry. Plenum Press, New York, New York, USA.

Weeden, C. R., A. M. Sheldon, and M. P. Hoffman. 1997. Biological control: a guide to natural enemies in North America. Cornell University, New York. 〈http:// www.nysaes.cornell.edu/ent/biocontrol/weedfeeders/agapeta.html

Wooton, J. T. 1994. The nature and consequences of indirect effects in ecological communities. Annual Review of Ecology and Systematics 25:443-466. 